\title{
Optical, physical and structural studies of vanadium doped $\mathrm{P}_{2} \mathrm{O}_{5}-\mathrm{BaO}-\mathrm{Li}_{2} \mathrm{O}$ glasses
}

\author{
R. Lakshmikantha ${ }^{a}$, N.H. Ayachit ${ }^{\mathrm{b}}$, R.V. Anavekar ${ }^{\mathrm{c}, *}$ \\ a Department of Physics, KLE Society's S.Nijalingappa College, Bangalore 560010, India \\ ${ }^{\mathrm{b}}$ Department of Physics, Rani Channamma University, Belagavi 591156, Karnataka, India \\ c Department of Physics, Bangalore University, Bangalore 560056, India
}

\section{A R T I C L E I N F O}

\section{Article history:}

Received 21 November 2012

Received in revised form

26 August 2013

Accepted 5 September 2013

Available online 11 October 2013

Keywords:

C. Differential scanning calorimetry (DSC)

C. Infrared spectroscopy

C. X-ray diffraction

D. Electron paramagnetic resonance (EPR)

D. Optical properties

\begin{abstract}
A B S T R A C T
Glasses in the compositions $\left(\mathrm{Li}_{2} \mathrm{O}\right)_{25}-(\mathrm{BaO})_{25}-\left(\mathrm{P}_{2} \mathrm{O}_{5}\right)_{50-x}-\left(\mathrm{V}_{2} \mathrm{O}_{5}\right)_{x}$ (with $x=0.5,1.0,1.5,2.0,2.5$, and $3.0 \mathrm{~mol}$ $\%$ ) have been prepared by the conventional melt quenching technique. X-ray powder diffractrogram show broad peaks which conforms glassy nature of the sample. Differential scanning calorimetry (DSC) thermograms show characteristic glass transition temperature $\left(T_{\mathrm{g}}\right)$ and it increases with increasing substitution of $\mathrm{V}_{2} \mathrm{O}_{5}$ for $\mathrm{P}_{2} \mathrm{O}_{5}$. The measured physical parameters like density, refractive index, ionic concentration and electronic polarizability are found to vary linearly with increasing $\mathrm{X}$. Infrared spectra exhibits few bands, which are attributed to $(\mathrm{P}=\mathrm{O})_{\mathrm{AS}},(\mathrm{P}=\mathrm{O})_{\mathrm{S}},(\mathrm{V}=\mathrm{O}),(\mathrm{P}-\mathrm{O}-\mathrm{P})_{\mathrm{AS}}, \mathrm{P}-\mathrm{O}-\mathrm{V},(\mathrm{P}-\mathrm{O}-\mathrm{P})_{\mathrm{AS}}$ and $\mathrm{O}-\mathrm{P}-\mathrm{O}$ vibrations. The optical absorption spectra of $\mathrm{VO}^{2+}$ ions in these glasses show three bands and are assigned to the ${ }^{2} \mathrm{~B}_{2} \rightarrow{ }^{2} \mathrm{E}^{2}{ }^{2} \mathrm{~B}_{2} \rightarrow{ }^{2} \mathrm{~B}_{1}$ and ${ }^{2} \mathrm{~B}_{2} \rightarrow{ }^{2} \mathrm{~A}_{1}$ transitions. Electron paramagnetic resonance spectra of all the glass samples exhibit resonance signals characteristic of $\mathrm{VO}^{2+}$ ions. The values of SpinHamiltonian parameters indicate that the $\mathrm{VO}^{2+}$ ions are present in octahedral sites with tetragonal compression and belong to $\mathrm{C}_{4 \mathrm{~V}}$ symmetry.
\end{abstract}

(c) 2013 Elsevier Ltd. All rights reserved.

\section{Introduction}

In general, phosphate glasses have a variety of technological applications due to their several unique properties such as high thermal expansion coefficient, low viscosity and high UV transmission [1]. Phosphate glasses doped with transitional metal (TM) ions are technologically important because of their semiconducting properties, optical absorption, electrical memory switching and photo-conducting properties. The properties that make phosphate glasses candidates for so many applications are related to their molecular-level structure [2-4]. A problem related to phosphate glasses containing TM oxides is related with their mixed dual role, as modifiers but also as network formers. It is demonstrated by means of Raman spectroscopy $[5,6]$ that tungsten, iron or vanadium ions act as network modifiers but also as network formers depending by their concentration in the glass matrix [7]. Semiconducting transition metal oxide glasses have gained importance in recent years due to their possible applications in various technological fields [8,9]. Among such glasses, the vanadate glasses are being widely used in memory and switching devices [10]. $\mathrm{V}_{2} \mathrm{O}_{5}$ is known to participate in the glass network with $\mathrm{VO}_{5}$ pyramidal structural units. Several vanadate glasses show

\footnotetext{
* Corresponding author. Tel.: +91 802296 1471/1473; fax: +91 8023219295 .

E-mail address: anavekar_271@yahoo.co.in (R.V. Anavekar).
}

semiconducting behavior having electrical conductivity in the range of $10^{-3}-10^{-5}(\Omega-\mathrm{cm})^{-1}$, which is known to be due to small polaron hopping [11]. More precisely, vanadium containing glasses are identified as the n-type semiconductors for low value of the $\mathrm{V}^{4+} / \mathrm{V}^{5+}$ ratio [11]. Electron paramagnetic resonance (EPR) yields information concerning valence state and local environment of implanted transition metal (TM) ions, as well as the nature of structural defects induced in the substrate by the implantation. EPR is also very sensitive to interactions among transition ions, and to the formation of both clusters and fine crystalline inclusions containing atoms of transition metals [12]. In the present investigation we have studied the structural changes that take place due to inter substitution of $\mathrm{V}_{2} \mathrm{O}_{5} \leftrightarrow \mathrm{P}_{2} \mathrm{O}_{5}$ in phosphate barium lithium glass network using $\mathrm{V}_{2} \mathrm{O}_{5}$ as probing oxide. These structural changes are discussed with help of DSC, optical absorption, IR and EPR studies.

\section{Experimental}

\subsection{Glass preparation}

The nominal compositions of the glasses examined here and their designations are listed in Table 1 . The glasses with compositions $\left(\mathrm{Li}_{2} \mathrm{O}\right)_{25}-(\mathrm{BaO})_{25}-\left(\mathrm{P}_{2} \mathrm{O}_{5}\right)_{50-x}-\left(\mathrm{V}_{2} \mathrm{O}_{5}\right)_{x}$ (with $x=0.5,1.0,1.5,2.0,2.5$, and $3.0 \mathrm{~mol} \%$ ) is chosen for the studies. The composition of the modifier 
Table 1

Glass matrix with glass code.

\begin{tabular}{lllll}
\hline Sample code & \multicolumn{2}{l}{$\mathrm{Mol}(\%)$} & & \\
\cline { 2 - 5 } & $\mathrm{Li}_{2} \mathrm{O}$ & $\mathrm{BaO}$ & $\mathrm{P}_{2} \mathrm{O}_{5}$ & $\mathrm{~V}_{2} \mathrm{O}_{5}$ \\
\hline V1 & 25 & 25 & 49.50 & 0.5 \\
V2 & 25 & 25 & 49.00 & 1.0 \\
V3 & 25 & 25 & 48.50 & 1.5 \\
V4 & 25 & 25 & 48.00 & 2.0 \\
V5 & 25 & 25 & 47.50 & 2.5 \\
V6 & 25 & 25 & 47.00 & 3.0 \\
\hline
\end{tabular}

in the glass system $\left(\mathrm{Li}_{2} \mathrm{O} / \mathrm{BaO}\right)$ is chosen in such a way that it avoids the hygroscopicity and extends the glass forming region. Analytical grade compounds of $\mathrm{NH}_{4} \mathrm{H}_{2} \mathrm{PO}_{4}, \mathrm{~V}_{2} \mathrm{O}_{5}, \mathrm{Li}_{2} \mathrm{CO}_{3}$ and $\mathrm{BaCO}_{3}$ were used as starting materials. All the chemicals were weighed accurately, ground to fine powder and mixed thoroughly. The batches were melted at $1150{ }^{\circ} \mathrm{C}$ in a porcelain crucible by placing them in an electrical furnace. The melts were then poured on a polished brass plate and pressed quickly with another plate. The glasses thus obtained were transparent and greenish in color with the thickness of $1.5 \mathrm{~mm}$. Samples were annealed at $200{ }^{\circ} \mathrm{C}$ in a furnace for $4 \mathrm{~h}$, in order to relieve the thermal stresses. Finally, the samples were cooled naturally.

\subsection{X-ray diffraction}

The X-ray diffraction patterns of powder glass samples are recorded for $2 \theta$ values between $10^{\circ}$ and $80^{\circ}$ at $2^{\circ} / \mathrm{min}$ using Philips diffractometer with $\mathrm{Cu} \mathrm{K} \alpha$ radiation.

\subsection{Measurement of density}

The densities $(\rho)$ of all the glasses are determined using the Archimedes method with xylene $\left(\rho=0.863 \mathrm{~g} / \mathrm{cm}^{3}\right)$ as an immersion fluid. The density of glass calculated according to the formula:

$\rho=\frac{W_{A}}{W_{A}-W_{X}} \times 0.863 \mathrm{~g} / \mathrm{cm}^{3}$

where $W_{A}$ is the weight of the sample in air, $W_{X}$ is the weight of the sample in xylene.

The molar volume $V_{\mathrm{m}}$ was calculated from molecular weight $M$ and density $\rho$ according to $V_{\mathrm{m}}=\mathrm{M} / \rho \mathrm{cm}^{3} / \mathrm{mol}$.

\subsection{Differential scanning calorimetry (DSC)}

DSC studies were carried out using Mettler Toledo DSC Star ${ }^{\mathrm{e}}$ System in $50-550{ }^{\circ} \mathrm{C}$ temperature range at the rate of $10{ }^{\circ} \mathrm{C} / \mathrm{min}$. For this, typically about $15-20 \mathrm{mg}$ of a sample in a platelet form was hermetically sealed in aluminum pans and placed in the head of the calorimeter along with a reference pan.

\subsection{Refractive index}

The refractive index of glass samples have been measured using a Portable Jewel Refractometer (Chlight Corporation China Model CL -1.30 to 1.80$)$ with sodium D-Line $(589 \mathrm{~nm})$ as source of radiation.

\subsection{Electron paramagnetic resonance}

The EPR spectra of crushed samples were recorded at room temperature on an EPR spectrometer (BRUKER) operating in the Xband frequencies $(9.305 \mathrm{GHz})$ with a modulation frequency of $100 \mathrm{kHz}$. The resonance line of DPPH with $g=2.0036$ was used as a field marker.

\subsection{Optical absorption}

The optical absorption spectra of the prepared samples were recorded at room temperature using a Perkin-Elmer UV-vis spectrometer in the wavelength range $300-900 \mathrm{~nm}$.

\subsection{Infrared spectra}

The IR spectra of the glasses were recorded at room temperature using Perkin-Elmer Spectrum GX using the $\mathrm{KBr}$ pellet disc method in the range $400-4000 \mathrm{~cm}^{-1}$. Approximately $0.1-1.0 \%$ sample is well mixed into $200-250 \mathrm{mg}$ fine $\mathrm{KBr}$ (alkali halide) powder and then finely pulverized and put into a pellet-forming die. A force of approximately 8 tons is applied under a vacuum of several $\mathrm{mm} \mathrm{Hg}$ for several minutes form transparent pellets. Degassing is performed to eliminate air and moisture from the $\mathrm{KBr}$ powder. Inadequate vacuum may result in easily broken pellets that scatter light. Before forming the $\mathrm{KBr}$ powder into pellets, pulverize it to 200 mesh max and then dry at approximately $110{ }^{\circ} \mathrm{C}$ for $2-3 \mathrm{~h}$. When performing measurements, the background can be measured with an empty pellet holder inserted into the sample chamber. However, background measurements on a pellet holder with a pellet of $\mathrm{KBr}$ only, that contains no sample, can correct for infrared light scattering losses in the pellet and for moisture adsorbed on the $\mathrm{KBr}$.

\section{Results and discussion}

Phosphate glasses are low melting temperature glasses $\left(\sim 1000^{\circ} \mathrm{C}\right)$. Visual inspection of crucible shows no chemical reaction between the melt and the crucible. UV-visible absorption spectra observed for all $\mathrm{V}_{2} \mathrm{O}_{5}$ doped samples show well defined absorption bands which are consistent with literature. Further, porcelain crucibles are recommended for phosphate glasses as it is known that phosphate melt reacts with the Platinum Crucible.

\subsection{Powder X-ray diffraction studies}

The X-ray diffraction pattern consists of a few broad peaks rather than sharp peaks, which is a sign of glassy material. All the prepared glass samples confirm the glassy nature. Fig. 1 shows the typical X-ray diffraction pattern of V1 glass sample.

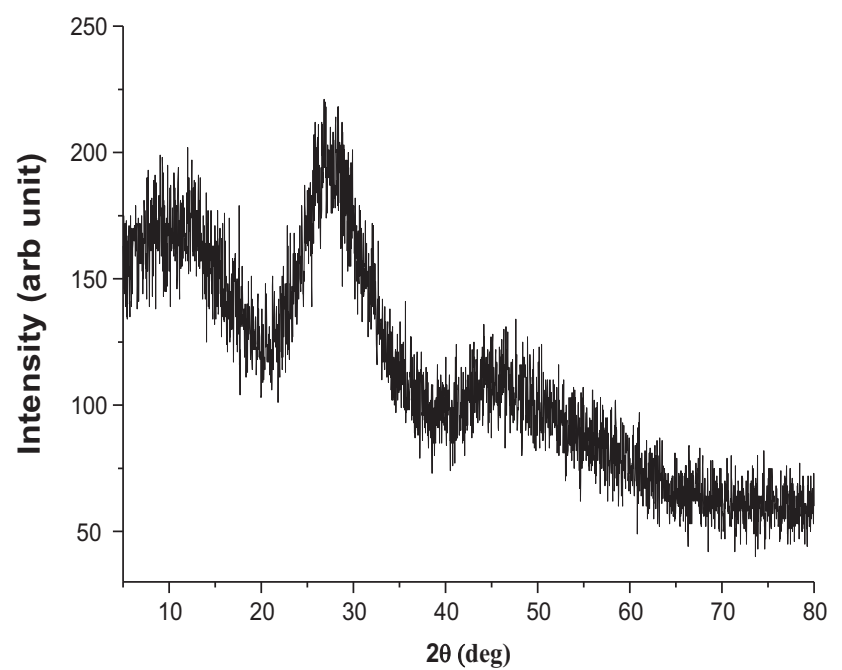

Fig. 1. X-ray diffraction pattern of a V1 glass sample. 
Table 2

Physical properties of $\mathrm{VO}^{2+}$ doped $\mathrm{V}$ series glass system at room temperature.

\begin{tabular}{|c|c|c|c|c|c|c|c|}
\hline \multirow[t]{2}{*}{ Sl.No } & \multirow[t]{2}{*}{ Physical property } & \multicolumn{6}{|c|}{ Glass code } \\
\hline & & V1 & V2 & V3 & V4 & V5 & V6 \\
\hline 1 & Average molecular weight (g/mol) & 125.790 & 125.991 & 126.325 & 126.660 & 126.994 & 127.328 \\
\hline 2 & Density $(\rho)\left(\mathrm{g} / \mathrm{cm}^{3}\right)( \pm 0.001)$ & 2.015 & 2.034 & 2.056 & 2.103 & 2.127 & 2.134 \\
\hline 3 & Mean atomic volume $\left(V_{\mathrm{M}}\right)\left(\mathrm{cm}^{3} / \mathrm{mol}\right)$ & 62.58 & 62.06 & 61.62 & 60.31 & 59.90 & 59.77 \\
\hline 4 & Refractive index $\left(n_{\mathrm{d}}\right)$ & 1.39 & 1.40 & 1.41 & 1.42 & 1.48 & 1.49 \\
\hline 5 & Molar refractivity $\left(R_{\mathrm{M}}\right)\left(\mathrm{cm}^{-3}\right)( \pm 0.005)$ & 14.835 & 15.046 & 15.268 & 15.263 & 17.0170 & 17.283 \\
\hline 6 & Optical dielectric constant, $(\varepsilon)( \pm 0.005)$ & 1.932 & 1.960 & 1.988 & 2.016 & 2.190 & 2.220 \\
\hline 7 & Reflection loss $( \pm 0.0002)$ & 0.02663 & 0.02778 & 0.02894 & 0.03012 & 0.03746 & 0.03873 \\
\hline 8 & Electronic polarizability $\left(a_{e}\right) \times 10^{-24}\left(\right.$ ions $\left./ \mathrm{cm}^{3}\right)( \pm 0.005)$ & 9.390 & 4.748 & 3.199 & 2.389 & 2.122 & 1.789 \\
\hline 9 & Vanadyl ions concentration $\left(N \times 10^{22}\right)\left(\right.$ ions $\left./ \mathrm{cm}^{3}\right)( \pm 0.005)$ & 0.603 & 1.219 & 1.849 & 2.529 & 3.196 & 3.859 \\
\hline 10 & Polaron radius $\left(r_{\mathrm{P}}\right)(\AA)( \pm 0.005)$ & 2.124 & 1.750 & 1.523 & 1.372 & 1.270 & 1.192 \\
\hline 11 & Inter-ionic distance $\left(r_{\mathrm{i}}\right)(\AA)( \pm 0.005)$ & 5.494 & 4.344 & 3.781 & 3.406 & 3.151 & 2.959 \\
\hline 12 & Glass transition temperature $\left(T_{\mathrm{g}}\right)\left({ }^{\circ} \mathrm{C}\right)( \pm 1)$ & 357 & 363 & 366 & 370 & 374 & 377 \\
\hline 13 & Thermal stability factor $\left({ }^{\circ} \mathrm{C}\right)( \pm 1)$ & $>193$ & $>187$ & $>184$ & $>180$ & $>176$ & $>173$ \\
\hline
\end{tabular}

\subsection{Physical properties}

The mean atomic volume $\left(V_{\mathrm{M}}\right)$ of each glass was obtained from the values of densities $(\rho)$ and mean atomic weights. The number of vanadyl ions per $\mathrm{cm}^{3}(N)$ was calculated from the glass composition and its density value. The calculated values are given in Table 2, along with other physical parameters.

The dielectric constant $(\varepsilon)$ was calculated from the refractive index of the glass using [13].

$\varepsilon=n_{\mathrm{d}}^{2}$

The reflection loss from the glass surface was computed from the refractive index by using Fresnel's formula as [14]

$R=\left(\frac{n_{\mathrm{d}}-1}{n_{\mathrm{d}}+1}\right)^{2}$

The molar refractivity $R_{\mathrm{M}}$ for each glass was evaluated using [15]

$R_{\mathrm{M}}=\left(\frac{n_{\mathrm{d}}^{2}-1}{n_{\mathrm{d}}^{2}+2}\right) \frac{M}{\rho}$

where $M$ is the average molecular weight and $\rho$ is the density in $\mathrm{gm} / \mathrm{cm}^{3}$.

The electronic polarizability $\alpha_{\mathrm{e}}$ was calculated using the formula [16]

$\alpha_{\mathrm{e}}=\frac{3\left(n_{\mathrm{d}}^{2}-1\right)}{4 \pi N\left(n_{\mathrm{d}}^{2}+2\right)}$

where $N$ is the number of vanadyl ions per unit volume.

The polaron radius and inter-ionic separation were calculated using the formulae [17]

$r_{\mathrm{p}}=\frac{1}{2}\left(\frac{\pi}{6 N}\right)^{1 / 3}$

and

$r_{\mathrm{i}}=\left(\frac{1}{N}\right)^{1 / 3}$

Density, refractive index, molar refractivity, ionic concentration, electronic polarizability, polaron radii and inter-ionic distances are evaluated. Density is found to increase while molar volume decreases with increasing substitution of $\mathrm{V}_{2} \mathrm{O}_{5}$ for $\mathrm{P}_{2} \mathrm{O}_{5}$. Since $\mathrm{V}_{2} \mathrm{O}_{5}$ has high molecular mass, therefore, it is an expected result. It can be noted from Table 2, the electronic polarizability decreases with the increase in $\mathrm{V}_{2} \mathrm{O}_{5}$ concentration, that is as the vanadyl ion concentration increases with increasing in $\mathrm{V}_{2} \mathrm{O}_{5}$ concentration. The contribution of ionic polarizability and orientation

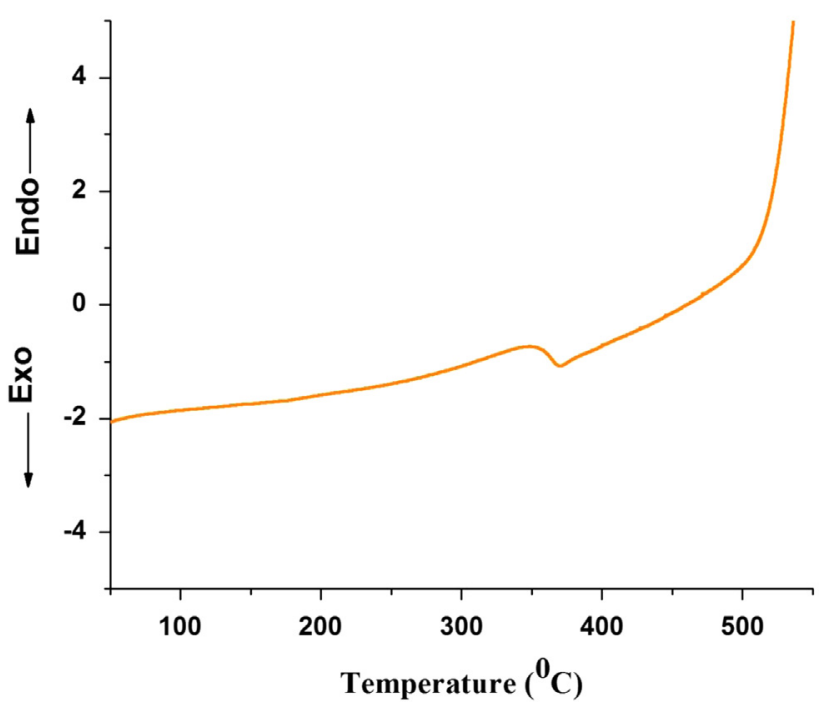

Fig. 2. DSC trace of $V_{2}$ glass.

polarizability is expected to be marginal. Since most of the bonds involved are covalent type [18].

\subsection{Differential scanning calorimeter}

From the DSC pattern, the values of glass transition temperature $\left(T_{\mathrm{g}}\right)$ and thermal stability factor $(\mathrm{S})$ presented in Table 2. In Fig. 2 typical DSC thermogram of V2 glass is shown. The variation of glass transition temperature $\left(T_{\mathrm{g}}\right)$ with $\mathrm{V}_{2} \mathrm{O}_{5}$ content $\left(\mathrm{V}_{2} \mathrm{O}_{5}\right)$ is presented in Fig. 3. Generally, the difference between crystallization temperature $\left(T_{\mathrm{c}}\right)$ and glass transition temperature $\left(T_{\mathrm{g}}\right)$, i.e., $\left(T_{\mathrm{c}}-T_{\mathrm{g}}\right)$ gives a measure of thermal stability of a supercooled liquid (glass). The larger value of $S$, the stronger is the inhibition to nucleation and crystallization processes, and consequently, the better thermal stability of supercooled liquids (glass) [19]. $T_{\mathrm{c}}$ could not be identified in the present work in all samples; due to limitation DSC operating system as maximum temperature that could be attained is $550{ }^{\circ} \mathrm{C}$. The stability factor of glasses investigated is in the range of $173-193{ }^{\circ} \mathrm{C}$ indicates glasses are stable against devitrification.

\subsection{Electron paramagnetic resonance}

Vanadium ions could be in $\mathrm{V}^{4+}$ and $\mathrm{V}^{5+}$ states in the $\mathrm{P}_{2} \mathrm{O}_{5}$ $\mathrm{BaO}-\mathrm{Li}_{2} \mathrm{O}$ glasses. During the melting of the glasses at higher 


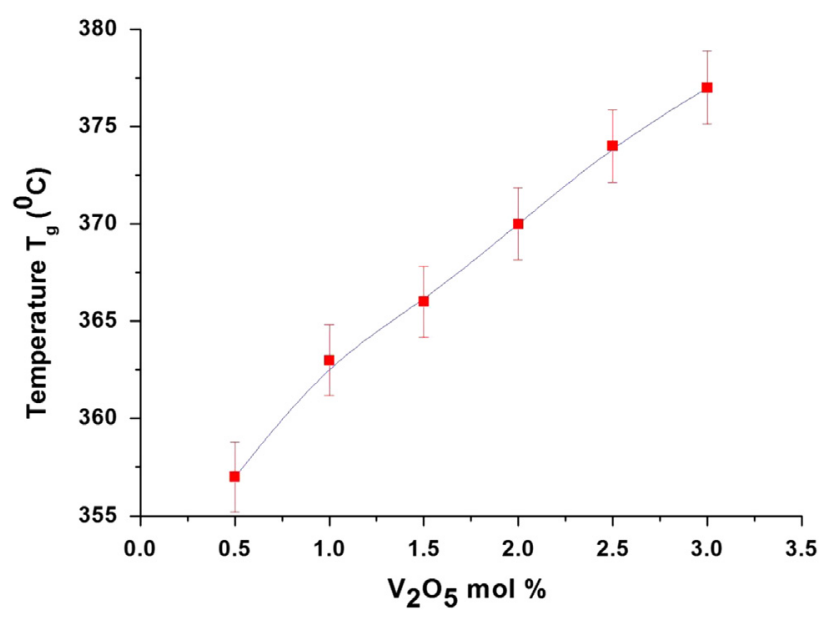

Fig. 3. Glass transition temperature vs. mol\% of $\mathrm{V}_{2} \mathrm{O}_{5}$ contents of $\mathrm{V}$-series glass system.

temperatures, there is a possibility for the following redox equilibrium to take place:

$2 \mathrm{~V}^{5+}+\mathrm{O}^{2-} \rightarrow 2 \mathrm{~V}^{4+}+\frac{1}{2} \mathrm{O}_{2} \uparrow$

Normally, one considers the ratio $\mathrm{V}^{4+} / \mathrm{V}_{\text {total }}$ lies in the range of 0.5-0.75 in the vanadate glasses and it increases with increasing $\mathrm{V}_{2} \mathrm{O}_{5}$. The $\mathrm{V}_{2} \mathrm{O}_{5}$ content of our samples are low, and this implies that ratio is about 0.5 .

To establish the presence of $\mathrm{V}^{4+}$ ions in the present glasses, we have recorded EPR and optical absorption spectra at the room temperature. EPR spectra show resolved hyperfine components arising from unpaired $3 \mathrm{~d}^{1}$ electron with ${ }^{51} \mathrm{~V}$ isotope $(I=7 / 2,100 \%$ abundance) and that they are very similar to those of the vanadyl ion, $\mathrm{VO}^{2+}$, which is known to accure in glasses doped with vanadium oxide. Although $\mathrm{V}^{4+}$ ion is usually 6-fold coordinated its local symmetry is generally not octahedral, but axially distorted to a tetragonal symmetry $\left(\mathrm{C}_{4 \mathrm{~V}}\right)$. This axial distortion of the octahedral is mainly responsible for the observed variation of the spectral parameters.

The EPR exhibit a well resolved typical hyperfine split spectrum due to ${ }^{51} \mathrm{~V}(I=7 / 2)$ as shown in Fig. 4. The spectrum is interpreted using axially symmetric spin Hamiltonian [20].

$\mathrm{H}=\beta g_{\|} \mathrm{H}_{\mathrm{Z}} \mathrm{S}_{\mathrm{Z}}+\beta g_{\perp}\left(\mathrm{H}_{\mathrm{X}} \mathrm{S}_{\mathrm{X}}+\mathrm{H}_{\mathrm{Y}} \mathrm{S}_{\mathrm{Y}}\right)+\mathrm{A}_{\|} \mathrm{S}_{\mathrm{Z}} \mathrm{I}_{\mathrm{Z}}+\mathrm{A}_{\perp}\left(\mathrm{S}_{\mathrm{X}} \mathrm{I}_{\mathrm{X}}+\mathrm{S}_{\mathrm{Y}} \mathrm{I}_{\mathrm{Y}}\right)$

where $\beta$ is the Bohr magneton while $\mathrm{g}_{\|}, \mathrm{g}_{\perp}$ and $\mathrm{A}_{\|}, \mathrm{A}_{\perp}$ are the components of the gyromagnetic tensor $g$ and hyperfine structure tensor A, respectively. $\mathrm{H}_{X}, \mathrm{H}_{Y}$ and $\mathrm{H}_{Z}$ are components of magnetic field, $S_{X}, S_{Y}$ and $S_{Z}$ and $I_{X}, I_{Y}$ and $I_{Z}$ are the components of the spin operators of the electron and the nucleus, respectively.

The magnetic field positions of the parallel and perpendicular hyperfine peaks taking into account the second order perturbation terms, are given by following equations [21]

$\mathrm{H}_{\|}(\mathrm{m})=\mathrm{H}_{\|}(0)-\mathrm{A}_{||} \mathrm{m}-\frac{\mathrm{A}_{\perp}^{2}}{2 \mathrm{H}_{\|}(0)}\left(\frac{63}{4}-\mathrm{m}^{2}\right)$

$\mathrm{H}_{\perp}(\mathrm{m})=\mathrm{H}_{\perp}(0)-\mathrm{A}_{\perp} \mathrm{m}-\frac{\left(\mathrm{A}_{\perp}^{2}+\mathrm{A}_{\perp}^{2}\right)}{4 \mathrm{H}_{\perp}(0)}\left(\frac{63}{4}-\mathrm{m}^{2}\right)$

where $\mathrm{m}$ is the magnetic quantum number of the vanadium nucleus, which takes the values $\pm \frac{7}{2}, \pm \frac{5}{2}, \pm \frac{3}{2}$ and $\pm \frac{1}{2}$. $\mathrm{H}_{\|}$and $\mathrm{H}_{\perp}$ are given by $\mathrm{H}_{\|}(0)=\frac{h \nu}{\mathrm{g}_{\|} \beta}$ and $\mathrm{H}_{\perp}(0)=\frac{h v}{\mathrm{~g}_{\perp} \beta}$, where $\beta$ is the Bohr magneton, $v$ is the spectrometer frequency.

The first approximation to $\mathrm{H}_{\|}(0)$ and $\mathrm{H}_{\perp}(0)$ were taken as the positions at which må 0 on a plotted curve of the experimentally observed lines vs. $\mathrm{m}$. Thus, we may find a first approximation to the second-order terms $\frac{A_{\perp}^{2}}{2 \mathrm{H}_{\|}(0)}$ and $\frac{\left(\mathrm{A}_{\perp}^{2}+\mathrm{A}_{\perp}^{2}\right)}{4 \mathrm{H}_{\perp}(0)}$.
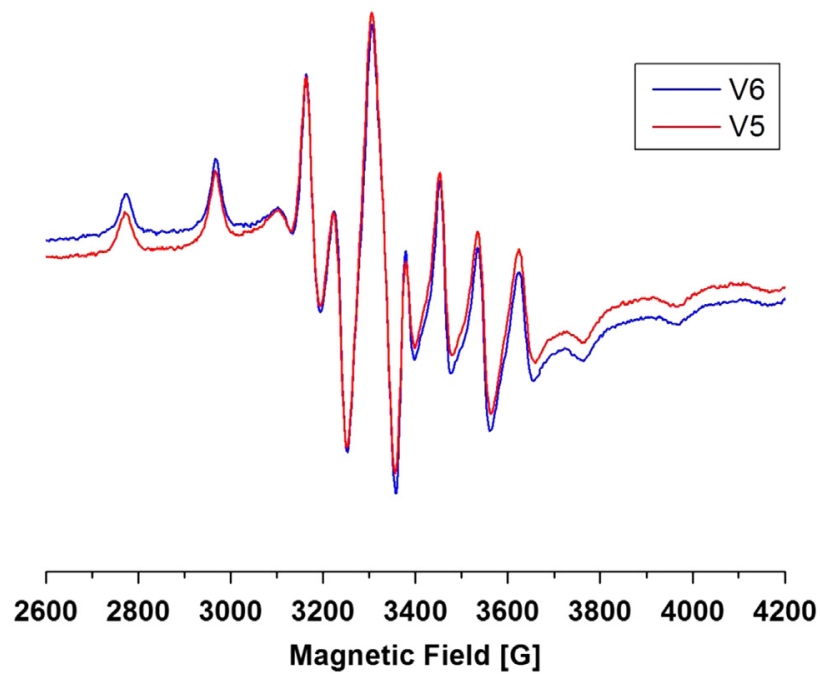

Fig. 4. EPR spectra of powder samples of $\mathrm{VO}^{2+}$ doped glass systems V5 and V6 at room temperature.

The spin Hamiltonian parameters $\mathrm{g}_{\|}, \mathrm{g}_{\perp}$ and $\mathrm{A}_{\|}, \mathrm{A}_{\perp}$ have been evaluated using the method given by Muncaster and Parke [21], and are listed in Table 3.

The spin-Hamiltonian parameters calculated for different mol\% $\mathrm{V}_{2} \mathrm{O}_{5}$ doped phosphate barium lithium glasses are typical of vanadyl ions $\left[\mathrm{g}_{\|}=1.8971, \mathrm{~g}_{\perp}=1.9608, \mathrm{~A}_{\|}=199.1257 \times 10^{-4} \mathrm{~cm}-1\right.$ and $A_{\perp}=75.9261 \times 10^{-4} \mathrm{~cm}-1$ ]. Hecht and Johnston [22] extensively studied the EPR and optical absorption spectra of $\mathrm{V}^{4+}$ ions in soda-boric oxide glasses and found that there are two possibilities either three-fold or four-fold symmetry to describe the crystal field of $\mathrm{V}^{4+}$ ions in glasses. A detailed analysis of the $\mathrm{g}$ tensor in the presence of trigonal symmetry was given by Gladney and Swalen [23]. An octahedral site with a tetragonal compression would give $g_{\|}<g_{\perp}<g_{e}$ QUOTE and $A_{\|}>\mathrm{A}_{\perp}[24,25]$. The $\mathrm{g}$ and $\mathrm{A}$ values obtained in the present work agree with this relationship and are close to those vanadyl complexes as reported by others [26-29]. It is therefore confirmed that the vanadyl ions in phosphate barium lithium glasses exist as $\mathrm{VO}^{2+}$ ions in octahedral coordination with a tetragonal compression and have $\mathrm{C}_{4 \mathrm{~V}}$ symmetry. A pictorial representation of the axially distorted tetragonal symmetry $\left(C_{4 v}\right)$ is shown in Fig. 5 . The bonding of the vanadyl ion in ligand field of octahedral symmetry has been well characterized by earlier workers $[23,27]$. The $\mathrm{V}^{4+}$ site in the $\mathrm{VO}^{2+}$ ion forms coplanar bonds with each of the four oxygen ligands. The vanadyl oxygen is attached axially above the $\mathrm{V}^{4+}$ site along the $z$-axis while the sixth oxygen forming the octahedral $\mathrm{O} \cdot \mathrm{VO}_{4} \cdot \mathrm{O}$ unit lies axially below the $\mathrm{V}^{4+}$ site.

The values of $\Delta g_{\|}$and $\Delta g_{\perp}$ are evaluated using the relation $\Delta g_{\|}=g_{e}-g_{\|} ; \Delta g_{\perp}=g_{e}-g_{\perp}$ which measures the tetragonality of the $\mathrm{VO}^{2+}$ and $\mathrm{g}_{\mathrm{e}}(=2.0023)$ is the $\mathrm{g}$ factor of free electrons. The values of $\Delta \mathrm{g}_{\|}, \Delta \mathrm{g}_{\perp}$ and $\Delta \mathrm{g}_{\|} / \Delta \mathrm{g}_{\perp}$ obtained for the glasses containing different concentration of $\mathrm{V}_{2} \mathrm{O}_{5}$ are presented in Table 3; the ratio is observed to decrease gradually with increase in the concentration of $\mathrm{V}_{2} \mathrm{O}_{5}$ for the given series of glasses. This implies that as the concentration increases show that the octahedral symmetry around $\mathrm{VO}^{2+}$ ions is improved.

Using EPR and optical parameters, the molecular bonding coefficient $\beta_{1}^{2}$ and $\varepsilon_{\pi}^{2}$ are evaluated using the following formulae [30]:

$\beta_{1}^{2}=\frac{\left(g_{e}-g_{||}\right) \Delta_{\|}}{8 \lambda \beta_{2}^{2}}$ 
Table 3

Spin Hamiltonian parameters of $\mathrm{VO}^{2+}$ at $\mathrm{RT} \mathrm{Li}_{2} \mathrm{O}-\mathrm{BaO}-\mathrm{P}_{2} \mathrm{O}_{5}$ glasses.

\begin{tabular}{|c|c|c|c|c|c|c|c|c|c|}
\hline Glass code & $g_{\|}$ & $g_{\perp}$ & $\mathrm{A}_{\|} \times 10^{-4}\left(\mathrm{~cm}^{-1}\right)$ & $\mathrm{A} \perp \times 10^{-4}\left(\mathrm{~cm}^{-1}\right)$ & $\Delta \mathrm{g}_{\|}$ & $\Delta \mathrm{g}_{\perp}$ & $\Delta g_{\|} / \Delta g_{\perp}$ & $\beta_{1}^{2}$ & $\varepsilon_{\pi}^{2}$ \\
\hline V1 & 1.8971 & 1.9608 & 199.1257 & 75.9261 & 0.1051 & 0.0414 & 2.539 & 1.417 & 1.989 \\
\hline V2 & 1.8966 & 1.9602 & 199.1976 & 75.7020 & 0.1057 & 0.0421 & 2.511 & 1.426 & 2.023 \\
\hline V3 & 1.8922 & 1.9542 & 199.9999 & 75.7020 & 0.1101 & 0.0480 & 2.294 & 1.485 & 2.307 \\
\hline V4 & 1.8922 & 1.9532 & 199.9999 & 74.7252 & 0.1101 & 0.0490 & 2.247 & 1.485 & 2.355 \\
\hline V5 & 1.8917 & 1.9517 & 199.6234 & 73.9926 & 0.1107 & 0.0506 & 2.188 & 1.490 & 2.432 \\
\hline V6 & 1.8917 & 1.9527 & 199.7557 & 74.9694 & 0.1106 & 0.0496 & 2.230 & 1.492 & 2.384 \\
\hline
\end{tabular}

The error in $\mathrm{g}$ and $\mathrm{A}$ values are \pm 0.004 and $3 \times 10^{-4} \mathrm{~cm}^{-1}$, respectively.

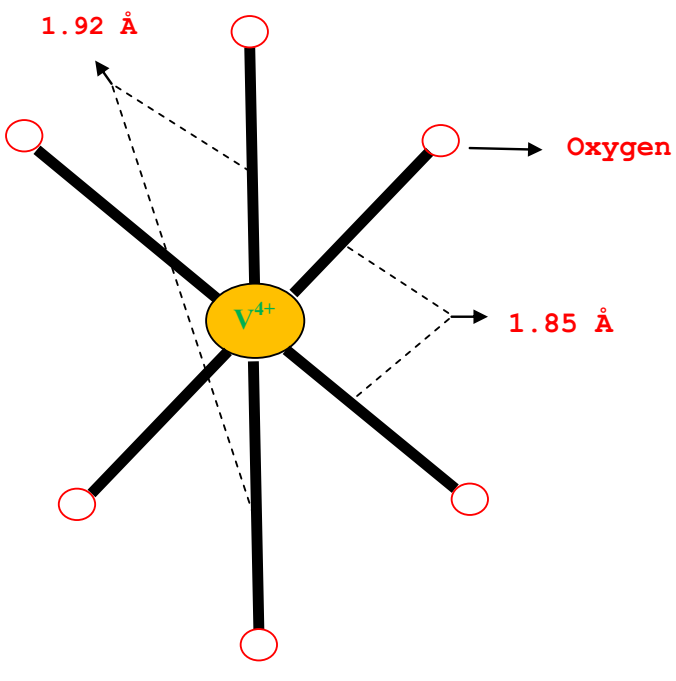

Fig. 5. A pictorial representation of the axially distorted tetragonal symmetry $\left(C_{4 v}\right)$.

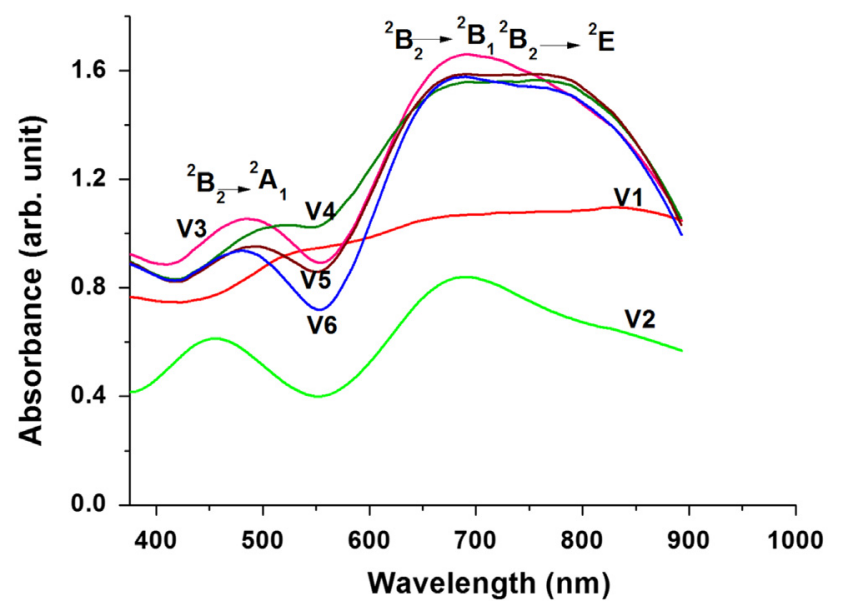

Fig. 6. Optical absorption spectra of V-series glasses.

$\varepsilon_{\pi}^{2}=\frac{\left(\mathrm{g}_{\mathrm{e}}-\mathrm{g}_{\perp}\right) \Delta_{\perp}}{2 \lambda \beta_{2}^{2}}$

where $\beta_{1}^{2}$ and $\varepsilon_{\pi}^{2}$ are the degrees of the in-plane $\mathrm{V}-\mathrm{O} \sigma$-bonds and of $\pi$-bonding with the vanadyl oxygen. $\Delta_{\|}$and $\Delta_{\perp}$ are the energies of the electronic transitions ${ }^{2} \mathrm{~B}_{2} \rightarrow{ }^{2} \mathrm{~B}_{1}$ and ${ }^{2} \mathrm{~B}_{2} \rightarrow{ }^{2} \mathrm{E}$, respectively. The free ion value of spin-orbit coupling constant for $\mathrm{VO}^{+2}$ is $\lambda=170 \mathrm{~cm}^{-1}$ and $\beta_{2}^{2}$ is assumed to be equal to 1 for the inplane $\pi$-bonding with the equilateral ligands [31]. Using Eqs. (11) and (12) the values of $\beta_{1}^{2}$ and $\varepsilon_{\pi}^{2}$ were calculated and are given in
Table 3. From the optical absorption spectra (Fig. 6), a small change in band maxima due to small structural change in the glass matrix with increase in $\mathrm{V}_{2} \mathrm{O}_{5}$ content is observed. The bands $\mathrm{i} \sigma$-bonds in agreement with a $\mathrm{C}_{4 \mathrm{~V}}$ local symmetry of isolated vanadium ions. The values $\beta_{1}^{2}$ and $\varepsilon_{\pi}^{2}$ are obtained from EPR and optical absorption data are consistent in the present investigation.

\subsection{Optical absorption}

The free ion ground state of $\mathrm{VO}^{2+}$ ion $\left(\mathrm{d}^{1}\right)$ is ${ }^{2} \mathrm{D}$. In a $\mathrm{V}-\mathrm{O}$ crystal field of octahedral $\left(\mathrm{O}_{\mathrm{h}}\right)$ symmetry, the $\mathrm{d}^{1}$ electron occupies the lower $t_{2}$ orbital and gives rise to the ${ }^{2} T_{2}$ ground state. In the excited state, the electron occupies the upper e orbital and gives rise to ${ }^{2} \mathrm{E}$ state [32]. However, in general, the non-symmetrical alignment of the VæO bond along the symmetry axis lowers its symmetry from $\mathrm{O}_{\mathrm{h}}$ to $\mathrm{C}_{4 \mathrm{v}}$ [33]. In a tetragonal crystal field $\left(\mathrm{C}_{4 \mathrm{v}}\right)$, the ${ }^{2} \mathrm{~T}_{2}$ level splits into ${ }^{2} \mathrm{~B}_{2}$ and ${ }^{2} \mathrm{E}$ and ${ }^{2} \mathrm{E}$ splits into ${ }^{2} \mathrm{~B}_{1}$ and ${ }^{2} \mathrm{~A}_{1}$. Thus for $\mathrm{V}^{4+}$ ion in tetragonal symmetry, one can expect three bands corresponding to the ${ }^{2} \mathrm{~B}_{2} \rightarrow{ }^{2} \mathrm{E}^{2} \mathrm{~B}_{2} \rightarrow{ }^{2} \mathrm{~B}_{1}$ and ${ }^{2} \mathrm{~B}_{2} \rightarrow{ }^{2} \mathrm{~A}_{1}$ transitions $[34,35]$. The general ordering of these energy levels is as follows: ${ }^{2} \mathrm{~B}_{2}<{ }^{2} \mathrm{E}<{ }^{2} \mathrm{~B}_{1}<{ }^{2} \mathrm{~A}_{1}$. Optical absorption spectra of $\mathrm{VO}^{2+}$ doped $\mathrm{V}$-series glasses are shown in Fig. 5. The three characteristic bands suggest that the distortion around the vanadyl ion can be attributed to tetragonally compressed octahedral site. The bands are attributed to the ${ }^{2} \mathrm{~B}_{2} \rightarrow{ }^{2} \mathrm{E},{ }^{2} \mathrm{~B}_{2} \rightarrow{ }^{2} \mathrm{~B}_{1}$ and ${ }^{2} \mathrm{~B}_{2} \rightarrow{ }^{2} \mathrm{~A}_{1}$ transitions. Positions and sequence of the bands in the optical spectrum in Fig. 5 is as follows: the very broad band at higher wavelength is a resulting of two bands. The first band $(780 \mathrm{~nm})$ is attributed to ${ }^{2} \mathrm{~B}_{2} \rightarrow{ }^{2} \mathrm{E}$ transition and the second one $(670 \mathrm{~nm})$ is related to ${ }^{2} \mathrm{~B}_{2} \rightarrow{ }^{2} \mathrm{~B}_{1}$ transition. The third band in decreasing wavelength direction corresponds to ${ }^{2} B_{2} \rightarrow{ }^{2} A_{1}(470 \mathrm{~nm})$. There is a noticeable shifting of the ${ }^{2} \mathrm{~B}_{2} \rightarrow{ }^{2} E$ and ${ }^{2} \mathrm{~B}_{2} \rightarrow{ }^{2} \mathrm{~B}_{1}$ bands towards higher wavelength side with a gradual hike in the intensity with increase in the concentration of $\mathrm{V}_{2} \mathrm{O}_{5}$. This observation clearly suggest that an increasing the presence of vanadyl ions with increase in the concentration of $\mathrm{V}_{2} \mathrm{O}_{5}$ in the glass system.

\subsection{Infrared spectra}

It is well known that $\mathrm{PO}_{4}$ tetrahedra are the basic structural units in phosphate glasses. The tetrahedral units are described by the $Q^{n}$ notation, where " $n$ " represents the number of bridging oxygens (BOs) that link neighboring P-tetrahedra [36]. Vitreous $\mathrm{P}_{2} \mathrm{O}_{5}$ structure has $\mathrm{Q}^{3}$ P-tetrahedra with three BOs and one double bonded oxygen $\mathrm{P}=\mathrm{O}$, forming a three-dimensional cross-linked network. Ultraphosphate glasses have both $\mathrm{Q}^{3}$ and $\mathrm{Q}^{2} \mathrm{P}$-tetrahedra structural units. Metaphosphate glasses have $\mathrm{Q}^{2} \mathrm{P}$-tetrahedra with two terminal oxygens that are shared with the modifying cation polyhedra. The $\mathrm{Q}^{2}$ tetrahedra link to form long chains (or rings). Phosphate glasses based on pyrophosphate $\left(\mathrm{Q}^{1}\right)$ and orthophosphate $\left(\mathrm{Q}^{0}\right)$ are also possible [37]. Van Wazer developed relationships that describe the compositional dependencies of the tetrahedral site distributions in binary alkali phosphate glasses [38]. The addition of a modifying oxide $\left(\mathrm{R}_{2} \mathrm{O}\right)$ to phosphate glass 


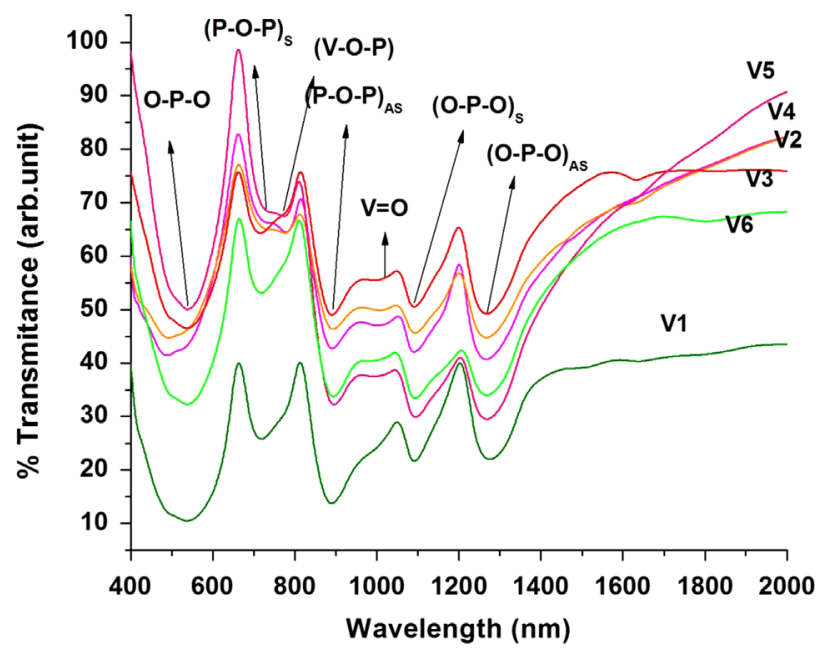

Fig. 7. Infrared transmission spectra of V series glasses.

depolymerizes the structure from ones with more highly crosslinked tetrahedra to ones with more non-bridging oxygens [NBOs] to maintain charge balance [38] which can be represented using relations,

$2 \mathrm{Q}^{3}+\mathrm{R}_{2} \mathrm{O} \rightarrow 2 \mathrm{Q}^{2}, 2 \mathrm{Q}^{2}+\mathrm{R}_{2} \mathrm{O} \rightarrow 2 \mathrm{Q}^{1}$ and $2 \mathrm{Q}^{1}+\mathrm{R}_{2} \mathrm{O} \rightarrow 2 \mathrm{Q}^{0}$

Infrared spectra of the glass samples are shown in Fig. 7. The characteristic features are the $\left(\mathrm{PO}_{2}\right)$ asymmetric stretching vibration band at $1263 \mathrm{~cm}^{-1}\left(\nu_{\mathrm{as}} \mathrm{PO}_{2}\right)$, the $\left(\mathrm{PO}_{2}\right)$ symmetric stretching vibration band at $1090 \mathrm{~cm}^{-1}\left(\nu_{\mathrm{s}} \mathrm{PO}_{2}\right)$, VåO vibration band at $1025 \mathrm{~cm}^{-1}$, the (POP) asymmetric stretching vibration band at $894 \mathrm{~cm}^{-1}$ ( $\nu_{\text {as }}$ POP), $(\mathrm{V}-\mathrm{O}-\mathrm{P})$ vibration band at $765 \mathrm{~cm}^{-1}$, the (POP) symmetric stretching vibration band at $738 \mathrm{~cm}^{-1}\left(\nu_{\mathrm{S}} \mathrm{POP}\right)$ [39-42]. The band located at $550 \mathrm{~cm}^{-1}$ is assigned to bending vibration of $\mathrm{O}-\mathrm{P}-\mathrm{O}$ linkages. In this glass system vanadium content is $\leq 3 \mathrm{~mol} \%$, therefore bands showed no shift. $(\mathrm{V}-\mathrm{O}-\mathrm{P}$ ) band is observed when $\mathrm{V}_{2} \mathrm{O}_{5}$ concentration $>1.5 \mathrm{~mol} \%$ [43].

\section{Conclusions}

Optical absorption spectra of the glass samples exhibits three absorption bands at 780, 670 and $470 \mathrm{~nm}$ are corresponding to ${ }^{2} \mathrm{~B}_{2} \rightarrow{ }^{2} \mathrm{E},{ }^{2} \mathrm{~B}_{2} \rightarrow{ }^{2} \mathrm{~B}_{1}$ and ${ }^{2} \mathrm{~B}_{2} \rightarrow{ }^{2} \mathrm{~A}_{1}$ transitions. The IR spectrum exhibits few bands, which are attributed to $(P=O),(P=O),(V=O)$ $(\mathrm{P}-\mathrm{O}-\mathrm{P}), \mathrm{P}-\mathrm{O}-\mathrm{V},(\mathrm{P}-\mathrm{O}-\mathrm{P})$ and $\mathrm{O}-\mathrm{P}-\mathrm{O}$ group vibrations respectively. The EPR results show that $\mathrm{g}_{\|}<\mathrm{g}_{\perp}<\mathrm{g}_{\mathrm{e}}(2.0023)$ and $A_{\|}>A_{\perp}$ for all glass samples studied in the present work. Therefore, it is confirmed that $\mathrm{V}^{4+}$ ions in these samples exist as $\mathrm{VO}^{2+}$ ions in tetragonally compressed octahedral site and belong to $\mathrm{C}_{4 \mathrm{~V}} \mathrm{sym}$ metry. The spin-Hamiltonian parameters $g$ and $A$ are found to be independent of $\mathrm{V}_{2} \mathrm{O}_{5}$ content. Decrease in $\Delta g_{\|} / \Delta g_{\perp}$ show that the octahedral symmetry around $\mathrm{VO}^{2+}$ ions is improved.

\section{References}

[1] B.C. Sales, Mater. Res. Soc. Bull. 12 (1987) 32

[2] C. Mercier, G. Palavit, L. Montagne, C. Follet, C.R. Chimie 5 (2002) 693.

[3] A. Mogus-Milankovic, A. Santic, S.T. Reis, K. Furic, D.E. Day, J. Non-Cryst. Solids 342 (2004) 97.

[4] R. Ravikumar, V. Rajagopal Reddy, A.V. Chandrasekhar, B.J. Reddy, Y.P. Reddy, P. S. Rao, J. Alloys Comp. 337 (2002) 272.

[5] N. Vedeanu, O. Cozar, I. Ardelean, S. Filip, J.Opt. Adv. Mater. 8 (3) (2006) 1135.

[6] H. Doweidar, Y.M. Moustafa, K. El-Egili, I. Abbas, Vib. Spectrosc. 37 (2005) 91.

[7] O. Cozar, D.A. Magdas, L. Nasdala, I. Ardelean, G. Damian, J. Non-Cryst. Solids 352 (2006) 3121.

[8] M. Pant, D.K. Kanchan, N. Gondaliya, J. Mater. Chem. Phys. 115 (2009) 98.

[9] W. Sung, J. Won, J. Lee, H. Kim, Mol. Crys. Liq. Crys. 499 (2009) 234.

[10] R.B. Rao, N. Veeraiah, Physica B 348 (2004) 256.

[11] A.I. Nicula, E. Culea, I. Lupsa, J. Non-Cryst. Solids. 79 (1986) 325.

[12] G.W. Arnold, P. Mazzoldi, Ion Beam Modification of Glasses, Elsevier, Amsterdam (1987) 1987; 195.

[13] B. Bendow, P.K. Benerjee, M.G. Drexhage, J. Lucas, J. Am. Ceram. Soc. 65 (1985) 92.

[14] Y. Ohisti, S. Mitachi, T. Tanabe, Phys. Chem. Glasses 24 (1983) 135

[15] J.E. Shelby, J. Ruller, Phys. Chem. Glasses 28 (1987) 262.

[16] A. Klonkowski, J. Non-Cryst. Solids 72 (1985) 117.

[17] M.M. Ahmed, C.A. Hogarth, M.N. Khan, J. Mater. Sci. Lett. 19 (1984) 4040.

[18] J. McCloy, B. Riley, B. Johnson, M. Schweiger, H.A. Qiao, N. Carlie, J. Am. Ceram. Soc. 93 (6) (2010) 1650.

[19] J. Zeng, J. Zhu, K. Zhou, J. Liu, Rear Met. 30 (2011) 126.

[20] S. Gupta, N. Khanijo, A. Mansingh, J. Non-Cryst.Solids 181 (1995) 58.

[21] R. Muncastar, S. Parke, J. Non-Cryst. Solids 24 (1977) 399.

[22] H.G. Hecht, T.S. Johnston, J. Chem. Phys. 46 (1967) 23.

[23] H.M. Gladney, J.D. Swalen, J. Chem. Phys. 42 (1965) 1999.

[24] A. Abragam, B. Bleaney, Electron Paramagnetic Resonance of Transition Ions, Clarendon Press, Oxford (1970) 1970; 175.

[25] R. Muncaster, S. Parke, J. Non-Cryst. Solids 24 (1977) 339.

[26] R.V. Anavekar, N. Devaraj, K.P. Ramesh, J. Ramakrishna, Phys. Chem. Glasses 33 (1992) 116.

[27] S. Gupta, N. Khanijo, A. Mansingh, J. Non-Cryst. Solids 181 (1995) 58.

[28] O. Cozar, I. Ardelean, V. Simon, G. Ilonca, C. Cracium, C. Cefan, J. Alloys Compd. 326 (2001) 124.

[29] J.E. Garbarczyk, L. Tykarski, P. Machowski, M. Wasiucionek, Solid State Ion. 140 (2001) 141.

[30] D. Kivelson, S. Lee, J. Chem. Phys. 41 (1964) 1896.

[31] B.R. McGarvey, in: R.L. Carlin (Ed.), Transition Metal Chemistry, vol. 3, Marcel Dekker, New York, 1966.

[32] B. Sumalatha, I. Omkaram, T. Rajavardhana Rao, Ch. Linga Raju, J. Mol. Struct. 1006 (2011) 96.

[33] I. Omkaram, R.P. Sreekanth Chakradhar, J. Lakshmana Rao, Physica B 388 (2007) 318.

[34] C.J. Ballhausen, Introduction to Ligand Field Theory, McGraw-Hill, New York, 1962.

[35] C.J. Ballhausen, H.B. Gray, Inorg. Chem. 1 (1962) 111.

[36] F. Liebau, Structure and Bonding in Crystals II, in: M.O. Keefe, A. Navrotsky (Eds.), Acad. Press, New York, 1981, p. 197.

[37] E. Metwalli, M. Karabulut, D.L. Sidebottom, M.M. Morsi, R.K. Brow, J. NonCryst. Solids 344 (2004) 128.

[38] J. Van Wazer, Phosphorus and its Compounds, vols. 1 and 2, Interscience, New York, 1951.

[39] K. Mayer, J. Non-Cryst. Solids 209 (1997) 227.

[40] A.M. Efimov, J.Non-Cryst. Solids 209 (1997) 209.

[41] L. Koudelka, P. Mosner, Mater. Lett. 42 (2000) 194.

[42] R.K. Brow, J. Non-Cryst. Solids 263-264 (2000) 1.

[43] N. Kerkouri, M. Haddad, M. Et-Tabirou, A. Chahine, L. Laanab, Physica B 406 (2011) 3142 . 